\title{
Proposal of Quinella ovalis gen. nov., sp. nov., Based on Phylogenetic Analysis
}

\author{
L. R. KRUMHOLZ, ${ }^{1} \dagger$ M. P. BRYANT, ${ }^{1,2 *}$ W. J. BRULLA, ${ }^{1} \ddagger$ J. L. VICINI, ${ }^{1} \S$ \\ J. H. CLARK, ${ }^{1}$ AND D. A. STAHL ${ }^{2,3}$ \\ Departments of Animal Sciences, ${ }^{1}$ Microbiology, ${ }^{2}$ and Veterinary Pathobiology, ${ }^{3}$ \\ University of Illinois, Urbana, Illinois 61801
}

\begin{abstract}
Quin's oval is a relatively large bacterium often seen in the rumens of sheep fed diets containing some readily fermented carbohydrates. It has not been obtained in axenic cultures, but a number of its features have been determined by various methods, such as studying cell suspensions purified from rumen fluid by differential centrifugation. We obtained similarly purified suspensions from a sheep fed a diet containing a large amount of molasses. Nearly complete 16S rRNA sequence analysis of these cells as well as cells of Selenomonas ruminantium subsp. ruminantium GA192 (ATCC 12561; type strain) and $S$. ruminantium subsp. lactilytica HD $_{4}$ (ATCC 27209) was done. These sequences were compared with those of other bacteria. Evolutionary distance estimates indicated that Quin's oval was most closely related to the Selenomonas-Megasphaera-Sporomusa group in the gram-positive phylum but that it belongs in a new genus. We propose the name Quinella ovalis gen. nov., sp. nov., with its description based on previously known features.
\end{abstract}

Quin's oval (QO) was briefly described by Woodcock and Lapage in 1913 (27) and separately discovered by Quin (16) in 1943. Quin found it in large numbers in the rumens of sheep fed diets of sugar-rich fresh alfalfa either alone or supplemented with molasses, sucrose, or glucose. Although he did not isolate it, he named it "Schizosaccharomyces ovis" because of its yeast-like (gassy) rapid fermentation of sugar, its relatively large (4-by-8 $\mu \mathrm{m})$ oval to oblong-oval shape, and its reproduction by binary fission. He also found that it produces glycogen intracellular reserve material from part of the sugar used.

Further studies on QO have been hampered by the inability of researchers to obtain pure cultures; however, a considerable number of its features have been determined by various techniques. For example, Howard and coworkers (2, 6,23 ) obtained highly enriched cells by differential centrifugation of rumen fluid from sheep fed diets that promoted the growth of large numbers of QO. Using these suspensions, they obtained information on the carbohydrate fermented and the products produced and definitive information on glycogen storage. They also determined that since the cell walls of QO were shown to contain 2,4-diaminopimelic and muramic acids, it is a bacterium. Other studies, such as those of Orpin (13), which used very slow and meticulous culture techniques, have confirmed and extended the information on carbohydrate fermentation, motility, gram-negative staining, and several other features.

QO is considered an important part of the microbiota of the rumens of sheep, and it occurs in numbers from $1.9 \times 10^{5}$ to $3.0 \times 10^{8} / \mathrm{ml}(13)$. It has been found in numbers as high as $10^{11} / \mathrm{ml}(21)$ in sheep fed mainly molasses.

While no taxonomic information has been published on QO since the definitive studies showing that it is a bacterium (23), one of us (M.P.B.) has long surmised that it is at least

\footnotetext{
* Corresponding author.

$\dagger$ Present address: Department of Civil Engineering, Massachusetts Institute of Technology, Cambridge, MA 02139.

$\ddagger$ Present address: 1320 Riverside Drive, Apartment 10, Fort Atkinson, WI 53538.

$\S$ Present address: Monsanto Agricultural Co., St. Louis, MO 63198.
}

somewhat related to Selenomonas ruminantium subspecies $(4,15)$. Its fermentation products, propionate and acetate, its glycogen reserve material and unusual flagellation, and its fermentation of mannitol $(2,13,15)$, which is specific to few rumen microbes, are similar $(6,14,15)$.

The information from these previous studies provides the essence of a phenotypic description for QO; thus, a phylogenetic assessment of the organism was done by 16S rRNA sequence analysis of cells purified from ruminal fluid by differential centrifugation.

Also, while 16S rRNA oligonucleotide cataloging indicated that Selenomonas, Sporomusa, and Megasphaera form a cluster in the gram-positive phylum (18), no sequencing of 16S rRNA of Selenomonas species has been done. Thus, we sequenced the RNA of $S$. ruminantium subsp. ruminantium and that of $S$. ruminantium subsp. lactilytica for comparison with that of QO in this study.

\section{MATERIALS AND METHODS}

Source of strains and preparation of cells. A sheep with a cannulated rumen was fed a diet consisting of pellets $(0.5 \mathrm{~kg}$; $80 \%$ alfalfa hay, $20 \%$ dry molasses) and a liquid molasses mixture $(2.5 \mathrm{~kg})$ twice daily (21). After the sheep had been on the diet for a 3-week period, QO dominated the rumen microbial population, and rumen contents were removed and strained through cheesecloth. Cells of QO were enriched from $500 \mathrm{ml}$ of rumen contents by differential centrifugation as previously described (23). The resulting cell pellet contained greater than $90 \%$ QO cells (cell count) as determined by phase-contrast microscopy, with the other morphotypes being small bacteria. These cells were frozen at $-20^{\circ} \mathrm{C}$ until needed for sequencing.

$S$. ruminantium subsp. ruminantium GA192 (ATCC $12561^{\mathrm{T}}$ ) and $S$. ruminantium subsp. lactilytica $\mathrm{HD}_{4}$ (ATCC 27209) were from the collection of M. P. Bryant. The anaerobic techniques used for cultivation were those of Hungate (8) as modified by Bryant (3) and Balch and Wolfe (1). The medium was composed of $30 \%$ (vol/vol) clarified rumen fluid and $0.2 \%$ (wt/vol) glucose, $0.1 \%$ cellobiose, $0.1 \%$ starch, $0.0002 \%$ resazurin, $0.05 \%$ cysteine $-\mathrm{HCl}, 0.05 \%$ $\mathrm{Na}_{2} \mathrm{~S} \cdot 9 \mathrm{H}_{2} \mathrm{O}, 0.4 \% \mathrm{CO}_{2}$-equilibrated $\mathrm{Na}_{2} \mathrm{CO}_{3}$, and minerals 


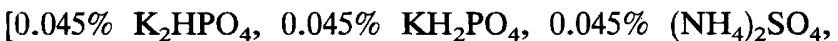
$\left.0.09 \% \mathrm{NaCl}, 0.019 \% \mathrm{MgSO}_{4} \cdot 7 \mathrm{H}_{2} \mathrm{O}, 0.012 \% \mathrm{CaCl}_{2} \cdot 2 \mathrm{H}_{2} \mathrm{O}\right]$.

Ribosomal purification and RNA sequencing. Cells were fractured by mechanical disruption with glass beads (19). Ribosomes were isolated on a sucrose step gradient, and the rRNA was isolated by phenol, phenol-chloroform (4:1), and chloroform extractions followed by ethanol precipitation $(10,19)$. Dideoxy nucleotide sequencing was carried out with reverse transcriptase and ${ }^{35} \mathrm{~S}-\mathrm{dATP}$ as described by Lane et al. (10) with three universal oligonucleotide primers (10). The remaining sequence was determined with four additional primers. Their sequences and complementary priming sites (Escherichia coli 16S rRNA numbering) are CTACGGG (G/A)(G/C)GCAGCAG (residues 342 to 357), TCTACGCAT TTCACC (residues 690 to 704), AGGGTTGCGCTCGTTG (residues 1100 to 1115), and GGGTACCTTGTTACG (resiclues 1496 to 1510 ).

Phylogenetic analysis. Sequences were aligned by using conserved features of the primary and secondary structures of 16S rRNA genes (26). Sequence similarities were calculated by comparing only those positions at which bases could be unambiguously aligned (approximately 1,300 bases). Evolutionary distances were calculated by the method of Jukes and Cantor (9).

A phylogeny was determined from the evolutionary distance by the algorithm of De Soete (5). This inferred phylogeny was consistent with that derived by a second method in which the optimal branching order was deduced by an iterative program that tested alternative branching orders that minimized tree error (12). Error was defined as the sum of the squares of the differences between the pairwise evolutionary distance estimates and the corresponding tree representation of the distance. Each difference was weighted by the corresponding statistical uncertainty of the distance estimate (12).

Nucleotide sequence accession numbers. GenBank accession numbers for the sequences for the various strains and species (Table 1 and Fig. 1) include M23928 (Lactobacillus casei), M23732 (Clostridium innocuum), M23731 (Clostridium ramosum), M23927 (Clostridium barkeri), M23930 (Clostridium pasteurianum), M23929 (Clostridium aminovalericum), M26494 (Clostridium sticklandii), M62701 (QO [Quinella ovalis]), M26493 (Megasphaera elsdenii), M62702 (S. ruminantium subsp. ruminantium), M62703 (S. ruminantium subsp. lactilytica), and M11212 (Heliobacterium chlorum).

\section{RESULTS AND DISCUSSION}

Analysis of the 16S rRNA sequence data (Table 1) shows the values for estimated evolutionary distances between QO 16S rRNA and those of other more or less related bacteria. The 16S rRNA sequence of QO is related to those of the gram-positive group, even though $\mathrm{QO}$ has a gram-negative ultrastructure (23). Similar relatedness within the grampositive groups has been found in the sequences of other gram-negative bacteria, such as those in the genera Selenomonas, Megasphaera, and Sporomusa, to which the sequence of QO is most closely related. On the basis of the $16 \mathrm{~S}$ rRNA oligonucleotide-cataloging technique, these three genera were previously demonstrated to form a distinct evolutionary group (18). QO has now been shown to belong to this group.

A phylogenetic tree, inferred from an evolutionary distance matrix (Table 1), illustrates the evolutionary distances among selected phylogenetically gram-positive Eubacteria

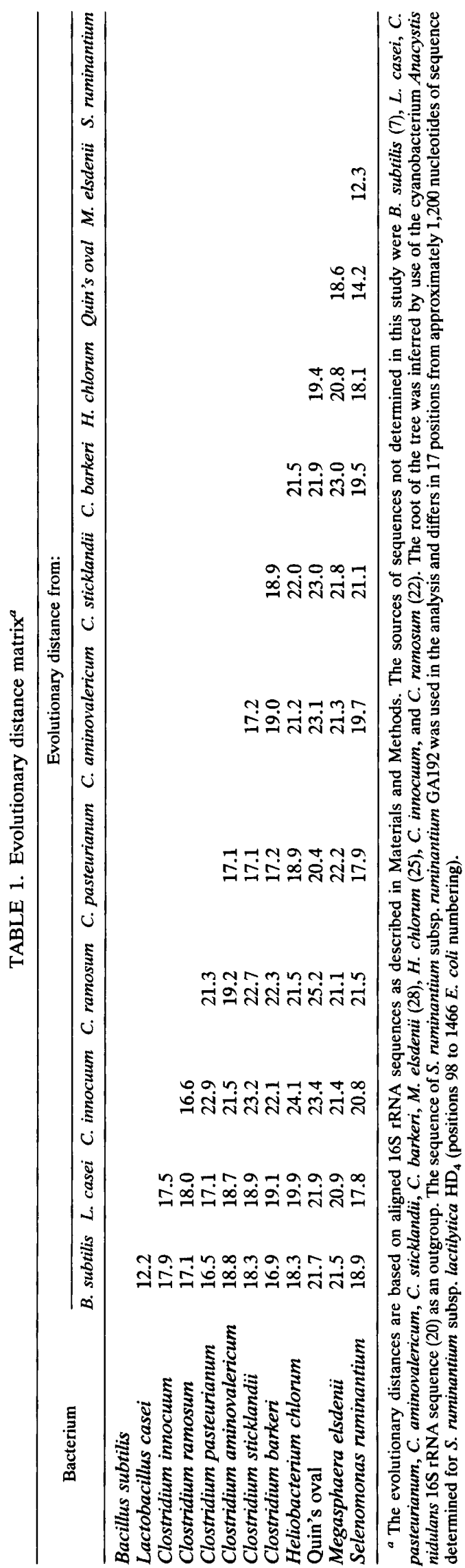




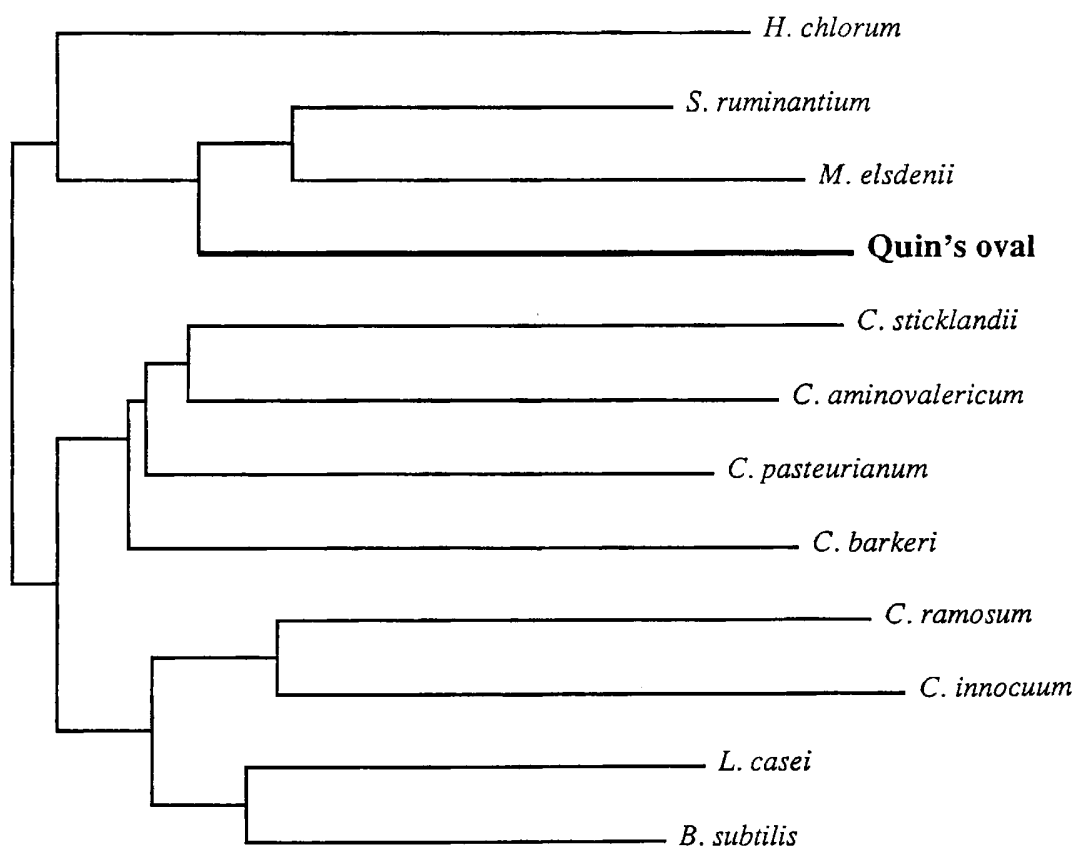

$10 \%$

FIG. 1. Phylogenetic relationship of QO to other selected bacteria. The phylogenetic tree was inferred from the evolutionary distance matrix (Table 1) by the algorithm of De Soete (5).

genera and their relationship to QO (Fig. 1). However, QO is not closely related to either $M$. elsdenii or $S$. ruminantium. Neither is it specifically related to Sporomusa paucivorans. The evolutionary distances separating $S$. paucivorans from QO, $M$. elsdenii, and $S$. ruminantium GA192 are 18.5, 14.8, and $13.2(24)$. Thus, QO is shown to be a distinct member of this assemblage of organisms that share a gram-negative ultrastructure but are affiliated with gram-positive bacteria. Absolute boundaries, based on 16S rRNA sequence similarities, have not been proposed for defining a genus, species, or higher taxons, nor may it be appropriate to do so, since a working taxonomy must consider both the phenotype and the phylogenetic position of the organism. However, on the basis of the evolutionary distances separating $\mathrm{QO}$ and its known relatives in relationship to distances separating other described genera, we propose that QO be placed in a separate genus and species.

Description of the new genus and species. Quinella gen. nov. Quinella (Quin.el'la. N.L. fem. n.) is named for the pioneering ruminologist, J. I. Quin (16), who described it in some detail. It includes nonsporing, heterotropic, mesophilic, anaerobic ovals with tumbling motilities and linear tufts of flagella on one side of their cells (14). The genus is gram negative, and its cell wall contains a distinct outer membrane and muramic and $m$-diaminopimelic acids (23). It reproduces by binary fission, and it usually occurs as singles and pairs. It ferments a small number of carbohydrates, and it produces lactate, acetate, propionate, and $\mathrm{CO}_{2}$ as the main fermentation products $(2,13)$ and glycogen-like reserve material (6).

The type species is $Q$. ovalis.

$Q$. ovalis sp. nov. The description of $Q$. ovalis sp. nov. (o.val'is. L. fem. adj., egg-shaped) is that of the genus plus the following. Cells are oval. They are about 3 to 4 by 5 to 8 $\mu \mathrm{m}$ in size but can be considerably smaller in the rumen if crowding occurs (21). Photomicrographs that represent the morphology have been published $(11,16,21,23)$.

The species has not been axenically cultivated, and therefore, this description is the type of the species (rule 18 in the International Code of Nomenclature of Bacteria). Highly enriched and partially purified cell suspensions ferment glucose, fructose, sucrose, and mannitol and slowly metabolize maltose. Polysaccharides, amino acids, proteins, lactate, melibiose, mannose, glucosamine, galactose, rhamnose, cellobiose, lactose, glucuronic acid, xylose, arabinose, and soluble starch are not fermented or are fermented at extremely low rates $(2,13)$.

Rapid growth occurs at 37 to $39^{\circ} \mathrm{C}$, and slow growth occurs at $44^{\circ} \mathrm{C}$. No growth occurs at 25 or $50^{\circ} \mathrm{C}(13)$. It grows in the rumen at $\mathrm{pH}$ values at least somewhat lower than 6.0. The higher $\mathrm{pH}$ limit is not known. It produces mainly lactic acid as a fermentation product when the sugar energy source is not limiting growth, but produces mainly acetate, propionate, and $\mathrm{CO}_{2}$ when the energy source is limiting and growth is slow (21), as does $S$. ruminantium (17). When it is by far the main organism in the rumens of sheep fed mainly molasses (21), acetate and propionate are the main organic acids produced and no lactate is detectable at any time during the 24-h feeding cycle.

$Q$. ovalis is observed in mesophilic, anaerobic, and rumen environments such as the rumens of sheep, but it is probably also widely distributed in other ruminants such as llamas (13). The number observed in the rumen is strongly influenced by the amount of fermentable sugars, such as glucose or sucrose, in the animal's diet $(2,13,16,21)$.

Relationships of $Q$. ovalis. Its closest relatives, on the basis of $16 \mathrm{~S}$ rRNA sequence analyses, are $S$. ruminantium subsp. ruminantium and $S$. ruminantium subsp. lactilytica, which 
as subspecies share approximately $98.8 \% 16 \mathrm{~S}$ rRNA sequence similarity (Table 1). These two subspecies are also similar to $Q$. ovalis in their fermentation products, but they differ from $Q$. ovalis in their abilities to ferment many more sugars, glycosides, and amino acids and in their curved-tohelical shape (4). The large selenomonad " $S$. ruminantium subsp. bryanti" differs from $Q$. ovalis as do the other two subspecies, except that it ferments fewer energy sources than the other two subspecies $(4,15)$. However, unlike $Q$. ovalis, it ferments both cellobiose and mannose. Cultures of $S$. ruminantium subsp. bryanti are not extant, so it would be quite difficult to obtain cells for 16S rRNA sequencing for comparison with the sequence of $Q$. ovalis.

Another rumen oval bacterium, "Magnoovum eadii," that produces glycogen reserves and the fermentation products lactate, acetate, propionate, and $\mathrm{CO}_{2}$ is similar to $Q$. ovalis in the above respects but differs greatly in that it is much larger, it has a gliding motility with a very large number of peritrichously arranged flagella, and, while it has a similarly gram-negative ultrastructure, it contains no ribose but does contain galactosamine in the cell wall (14).

\section{ACKNOWLEDGMENTS}

We thank Carl Woese for the provision of certain primers and unpublished data on the 16S rRNA sequence of $S$. paucivorans and Thomas MacAdoo, Virginia Polytechnic Institute and State University, for great help in naming $Q$. ovalis.

This research was supported by grant $35-331$ to M.P.B. from the U.S. Department of Agriculture, by contract DE-AC02-81ER10874 to M.P.B. from the U.S. Department of Energy, by cooperative agreement CR812496-02 to D.A.S. from the U.S. Environmental Protection Agency, and by the Agricultural Experimental Station of the University of Illinois, Urbana-Champaign.

\section{REFERENCES}

1. Balch, W. E., and R. S. Wolfe. 1976. New approach to the cultivation of methanogenic bacteria: 2-mercaptoethanesulfonic acid (HS-CoM)-dependent growth of Methanobacterium ruminantium in a pressurized atmosphere. Appl. Environ. Microbiol. 32:781-791.

2. Brough, B. E., T. C. Reid, and B. H. Howard. 1970. The biochemistry of the rumen bacterium "Quin's oval." Part 1. Fermentation of carbohydrates. N. Z. J. Sci. 13:570-575.

3. Bryant, M. P. 1972. Commentary on the Hungate technique for culture of anaerobic bacteria. Am. J. Clin. Nutr. 25:1324-1328.

4. Bryant, M. P. 1984. Genus IX. Selenomonas Von Prowazek, p. 650-653. In N. R. Kreig (ed.), Bergey's manual of systematic bacteriology, vol. 1. Williams and Wilkins, Baltimore.

5. De Soete, G. 1973. A least-squares algorithm for fitting additive trees to proximity data. Psychometrika 48:621-626.

6. Every, D. D., and B. H. Howard. 1970. The biochemistry of the rumen bacterium “Quin's oval." Part 3. The storage polysaccharide. N. Z. J. Sci. 13:584-590.

7. Green, C. J., G. C. Stewart, M. A. Hollis, B. S. Vold, and K. F. Bott. 1985. Nucleotide sequence of Bacillus subtilis ribosomal RNA operon, $m m B$. Gene 37:261-266.

8. Hungate, R. E. 1950. The anaerobic mesophilic cellulolytic bacteria. Bacteriol. Rev. 14:1-49.

9. Jukes, T. H., and C. R. Cantor. 1969. Evolution of protein molecules, p. 21-132. In H. N. Munro (ed.), Mammalian protein metabolism. Academic Press, Inc., New York.

10. Lane, D. J., B. Pace, G. J. Olsen, D. A. Stahl, M. Sogin, and N. R. Pace. 1985. Rapid determination of 16 S ribosomal RNA sequences for phylogenetic analysis. Proc. Natl. Acad. Sci. USA 82:6955-6959.

11. McGaughey, C. A., and K. C. Sellers. 1948. Microflora of the rumen. Nature (London) 161:1014-1015.

12. Olsen, G. J., D. J. Lane, S. J. Grovannoni, N. R. Pace, and D. A. Stahl. 1986. Microbial ecology and evolution. A ribosomal RNA approach, p. 337-365. In L. N. Ornston, A. Balows, and P. Bauman (ed.), Annual reviews of microbiology, vol. 40. Annual Reviews, Inc., Palo Alto, Calif.

13. Orpin, C. G. 1972. The culture in vitro of the rumen bacterium Quin's oval. J. Gen. Microbiol. 73:523-530.

14. Orpin, C. G. 1976. The characterization of the rumen bacterium Eadies' oval, Magnoovum gen. nov. eadii sp. nov. Arch. Microbiol. 111:155-159.

15. Prins, R. A. 1971. Isolation, culture and fermentation characteristics of Selenomonas ruminantium var. bryanti. J. Bacteriol. 105:820-825.

16. Quin, J. I. 1943. Studies on the alimentary tracts of merino sheep in south Africa. VII. Fermentation in the forestomachs of sheep. Onderstepoort J. Vet. Sci. Anim. Ind. 18:91-112.

17. Scheifinger, C. C., M. J. Latham, and M. J. Wolin. 1975. Relationship of lactate dehydrogenase specificity and growth rate to lactate metabolism by Selenomonas ruminantium. Appl. Microbiol. 30:916-921.

18. Stackebrandt, E., H. Pohla, R. Kroppenstedt, H. Hippe, and C. R. Woese. 1985. 16S rRNA analysis of Sporomusa, Selenomonas, and Megasphaera: on the phylogenetic origin of grampositive eubacteria. Arch. Microbiol. 143:270-276.

19. Stahl, D. A., B. Flesher, H. R. Mansfield, and L. Montgomery. 1988. Use of phylogenetically based hybridization probes for studies of ruminal microbial ecology. Appl. Environ. Microbiol. 54:1079-1084.

20. Tomioka, N., and M. Sugiura. 1983. The complete nucleotide sequence of a 16S ribosomal RNA from a blue-green alga, Anacystis nidulans. Mol. Gen. Genet. 191:46-50.

21. Vicini, J. L., W. J. Brulla, C. L. Davis, and M. P. Bryant. 1987. Quin's oval and other microbiota in the rumens of molasses-fed sheep. Appl. Environ. Microbiol. 53:1273-1276.

22. Weisburg, W. G., J. G. Tully, D. L. Rose, J. P. Petzel, H. Oyaizu, D. Yang, L. Mandelco, J. Sechrest, T. G. Lawrence, J. Van Etten, J. Maniloff, and C. R. Woese. 1989. A phylogenetic analysis of the mycoplasmas: basis for their classification. J. Bacteriol. 171:6455-6467.

23. Wicken, A. J., and B. H. Howard. 1967. On the taxonomic status of “Quin's oval” organisms. J. Gen. Microbiol. 47:207-211.

24. Woese, C. R. (University of Illinois). 1990. Personal communication.

25. Woese, C. R., B. Debrunner-Vossbrink, H. Oyaizu, E. Stackebrandt, and W. Ludwig. 1985. Gram-positive bacteria: possible photosynthetic ancestry. Science 229:762-765.

26. Woese, C. R., R. Gutell, R. Gupta, and H. F. Noller. 1983. Detailed analysis of the higher order structure of 16S-like ribosomal ribonucleic acid. Microbiol. Rev. 47:621-669.

27. Woodcock, H. M., and G. Lapage. 1913. On a remarkable type of protistan parasite. Q. J. Microsc. Sci. 59:431-458.

28. Zhao, H., D. Yang, C. R. Woese, and M. P. Bryant. 1990. Assignment of Clostridium bryantii to Syntrophospora bryantii gen. nov., comb. nov. on the basis of a 16S rRNA sequence analysis of its crotonate-grown pure culture. Int. J. Syst. Bacteriol. 40:40-44. 